\title{
O singular monumento funerário romano de Soure (Conventus Scallabitanus)
}

\author{
The singular roman funerary monument from Soure \\ (Conventus Scallabitanus)
}

\author{
José d'ENCARNAÇÃO*
}

\begin{abstract}
RESUMO
ABSTRACT

Retoma-se o estudo epigráfico do monumento romano de Soure (HEp, 6 , 1996, 1037), salientando a importância da representação, em baixo relevo, da cena de caça à lebre e o elevado interesse histórico-cultural da referência a laquearia, como elemento arquitectónico integrante do monumento.

PALAVRAS CHAVE

Caça à lebre; sarcófagos; laquearia;

Conimbriga.

Epigraphic analysis of a roman monument (HEp, 6, 1996, 1037) found at Soure, near Conimbriga, in Lusitania. The great significance of the representation, in basso relief, of a hunting hare's scene. The funerary monument had laquearia (panelled ceiling), a very significant mark of an uncommon erudition and culture.

\section{KEYWORDS}

Roman hare's hunting; sarcophages; laquearia; Conimbriga.
\end{abstract}

Recibido el 30 de agosto de 2012. Aceptado el 17 de septiembre de 2012

A facilidade de comunicação de que dispomos e a partilha que, mui gostosamente, se pratica entre a grande maioria dos epigrafistas e investigadores da Antiguidade possibilitam oportuna revisão de leituras e mais adequado enquadramento histórico.

Recordo, por exemplo, como a expressão Romae sepultus, patente numa epígrafe de Conimbriga, ${ }^{1}$ poderá ter causado, a princípio, alguma surpresa, ainda que a epígrafe anterior desse corpus ( $n^{\circ}$ 33) também se refira a alguém que fora in itinere urbis defunctus et sepultus, por sinal com a intervenção de um collegium sa-

* CEAUCP - Centro de Estudos Arqueológicos das Universidades de Coimbra e Porto — Palácio de Sub-Ripas - P-3000-39 COIMBRA. Endereço privado: Rua Eça de Queirós, 89 — Pampilheira - P-2750-662 CASCAIS. jde@fl.uc.pt

1 ÉtIEnNe, Robert, FABRE, Georges e LÉVÊQUe, Pierre et Monique, Fouilles de Conimbriga, vol. II: Épigraphie et Sculpture. Paris, De Boccard, 1976, inscrição no 34 (pp. 62-63). 
lutare, e tal haja apontado, de imediato, a um relacionamento estreito, a nível pessoal e, até, institucional, entre esta cidade do conventus Scallabitanus e a capital do Império.

A descoberta em Roma, por Silvio Panciera, de uma «base onoraria larga più di $2 \mathrm{~m}$., quindi verosimilmente di statua equestre, che un paio di città (lusitane entrambe?) hanno fatto porre nella casa di un loro patrono sul Quirinale, a tal fine mandando ciascuna a Roma almeno due suoi cittadini come legati», tendo um deles uma identificação de tipo indígena — Silo Andronici (filius) — e sendo uma das cidades a civitas Conimbrigens[ium?], ${ }^{2}$ mais reforçou essa ideia, pelo que não causou admiração que um outro epitáfio, datável do século I, recentemente interpretado e encontrado em reaproveitamento num paço perto da cidade, perpetuasse a memória de Iulius Fortunatus, Romae sepultus. ${ }^{3} \mathrm{E}$ abriram-se-nos novas perspectivas, até para melhor se enquadrar o ager Conimbricensis.

Da excepcional importância cultural da villa romana do Rabaçal, sita a poucos quilómetros de Conimbriga, fala, por exemplo, a excelência dos seus mosaicos, completamente fora do comum no panorama da Lusitânia, a indiciar um nível cultural elevado. ${ }^{4}$

Todas essas circunstâncias induziram-me a retomar o estudo de uma epígrafe já publicada, ${ }^{5}$ mas que — para além de a sua análise epigráfica propriamente dita não ter sido feita-merecerá, decerto, que sobre ela se teçam mais considerações, pois dá a impressão de que terá passado quase despercebida.

Na verdade, nessa comunicação procurei sobretudo chamar a atenção para o tipo de decoração referida no texto epigráfico —os laquearia-, vocábulo de maior ocorrência em textos literários que epigráficos.

Cristina Isabel Lapo Oliveira, residente em Soure e minha aluna de Seminário no ano de 1993-1994, aproveitou o ensejo para fazer sobre a peça o relatório final,

2 PANCIERA, Silvio, «Domus a Roma. Altri contributi alla loro inventariazione», in Serta Antiqua et Mediaevalia, 6, 2003, pp. 368-373. Ver também ENCARNAÇÃO, José d', «Lusitani nell'Italia romana», in SARTORI, António, e VALVO, Alfredo [coord.], Hiberia — Italia / Italia — Hiberia (Actas do Convegno Internazionale di Epigrafia e Storia Antica - Gargnano-Brescia - 28-30 aprile 2005), Milano, 2006, pp. 5051.

3 ENCARNAÇÃO, José d', e CORREIA, Virgílio Hipólito, «Inscrições romanas no Paço da Ega (Condeixa-a-Nova) (Conimbriga - Conventus Scallabitanus)», Ficheiro Epigráfico, 98, 2012, inscrição no 443 [Acessível em: http://hdl.handle.net/10316/20220].

${ }_{4}$ Miguel Pessoa, o arqueólogo responsável pelo sítio, tem vindo a publicar bastantes artigos e opúsculos sobre o sítio, de que a sua dissertação de doutoramento, intitulada Villa Romana do Rabaçal, Penela, Portugal - Um Centro na Periferia do Império e do Território da Civitas de Conimbriga, defendida, a 12 de Julho de 2012, na Faculdade de Ciências Humanas e Sociais da Universidade Nova de Lisboa, quando publicada, se fará eco e será adequada síntese.

5 Publiquei uma primeira notícia na imprensa (ENCARNAÇÃO, José d', «Soure - Identificados importantes monumentos epigráficos romanos», Diário de Coimbra, 23-6-1987, p. 5) e apresentei o monumento na comunicação «L'épigraphie du village à l'extrême Occident d'Hispania», L'Epigrafia del Villaggio, (Actas do VII Colloquio Internazionale sul Tema L'Epigrafia del Villaggio, organizado em Forlì, em 27-30.09.1990). Faenza, 1993, pp. 253-255. [Acessível em: http://hdl.handle.net/10316/20640]. 
intitulado «O sarcófago romano de Soure». A minha ideia foi, desde logo, que também esse trabalho, mutatis mutandis, viesse a ser publicado, dado que abordava, com a exaustividade então possível, a problemática fundamental levantada pelo monumento encontrado, em Outubro de 1985, por ocasião dos trabalhos arqueológicos preliminares à pavimentação do largo sito a nascente do castelo, no cemitério medieval da igreja de Santa Maria de Finisterra; contudo, tal desiderato nunca chegou a concretizar-se e deposito agora o manuscrito original, para consulta, no arquivo do próprio Museu Municipal de Soure, onde o monumento se encontra exposto (№ de inventário: M-E-6). ${ }^{6}$

Helena Paula de Carvalho preparava, na mesma altura, as suas provas de capacidade científica na Universidade dos Açores sobre escultura funerária e, por isso, sob o no 11 (p. 70) incluiu aí os dados da peça, e teceu breves considerações na p. 81 , a reforçar a ideia de estarmos, «muito provavelmente» perante «um edifício tumular com mármore e decorações de tecto»; uma versão desse trabalho académico viria a ser publicada depois. ${ }^{7}$

Manuela Alves Dias, uma das responsáveis pela redacção de Hispania Epigraphica, sintetizou todos esses dados em HEp, 6, 1996, 1037 -donde passaria para a sua edição on line [ http://eda-bea.es/ ], registo no 23325 . Pela pesquisa que fiz, o monumento não chegou, porém, a ser incluído no habitual repertório de L'Année Épigraphique- daí talvez também a escassa repercussão que teve o seu achamento.

\section{A DECORAÇÃO}

Do monumento, de mármore que reputo passível de ser do tipo Estremoz/Vila Viçosa, restam dois fragmentos (Figs. 1 e 2) que, para efeitos da exposição no Museu, se colaram (Fig. 3). Dimensões: $(16,5) \times(123,5) \times 78,5 \mathrm{~cm}$.

Sucessivas reutilizações anteriores fizeram com que dele se perdesse boa parte, o que impossibilita, por outro lado, uma afirmação garantida acerca da sua tipologia. Servia de tampa a um sarcófago medieval, quando foi encontrado, mas isso não justifica, por si só, a primeira classificação que adiantei: é um sarcófago. De facto, a uma primeira vista, atendendo ao facto de as cenas de caça serem frequentes na face principal dos sarcófagos romanos, essa foi a impressão; todavia, uma observação mais atenta do conteúdo do texto pode levar-nos a outra conclusão.

6 Junta-se, assim, ao relatório de estágio, aí também depositado, elaborado por João Albertino de Matos Pereira Marujo, no quadro do Curso de Especialização em Assuntos Culturais no âmbito das Autarquias (1991-1993), intitulado Inventário do Património Artístico do Concelho de Soure, datado de Dezembro de 1993, em cuja pág. 17 se faz referência ao monumento.

7 CARVALHO, Helena Paula Abreu de, «Contribuição para o estudo da escultura funerária de época romana encontrada em Portugal», Cadernos de Arqueologia, Série II, Vols. 10-11, 1993/94, pp. 65-90. 


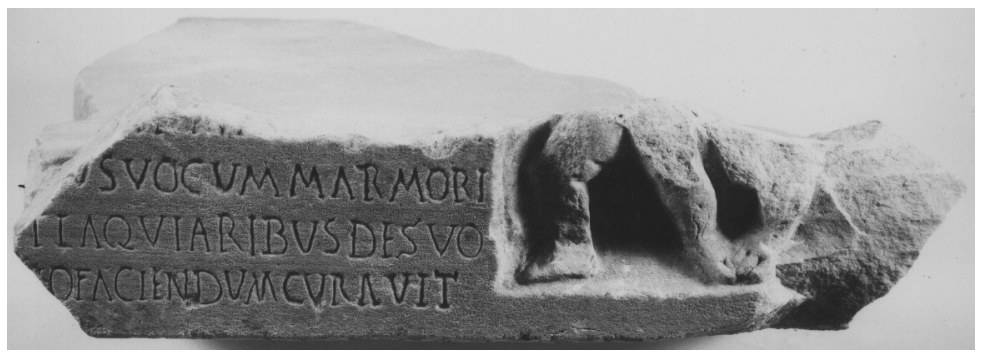

Fig. 1 - Fragmento da esquerda, com inscrição e parte da cena de caça. Foto de Delfim Ferreira.

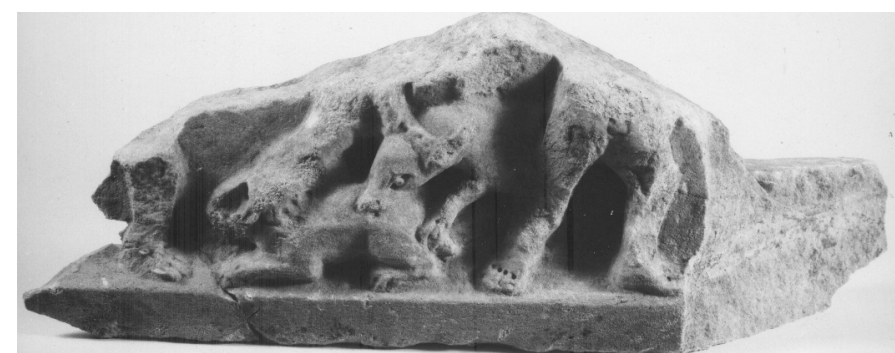

Fig. 2 - Fragmento da direita, com cena de caça à lebre. Foto de Delfim Ferreira.

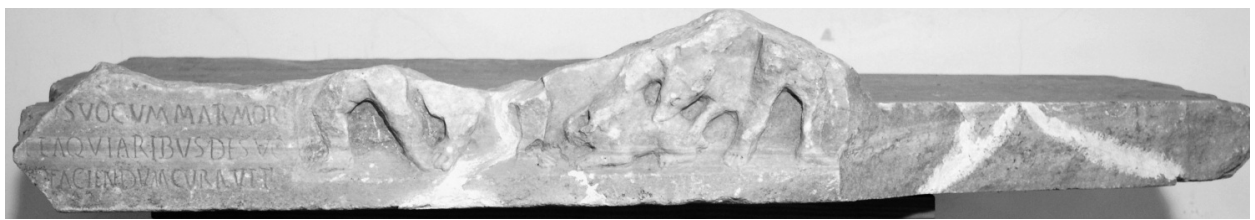

Fig. 3 - Apresentação do monumento no Museu Municipal de Soure. Foto gentilmente cedida pelo Museu.

Temos mais de três linhas incompletas de inscrição, que ocupam a parte esquerda, acompanhada, à direita, de pouco menos que metade (em altura) de uma cena de caça, em baixo-relevo. Restam as pernas desnudadas de um homem, até ao nível da coxa: a direita assenta bem no chão, está levemente flectida; a esquerda, também alvo de maus-tratos, está oblíqua, para trás, a dar a sensação de movimento: a personagem prepara-se para avançar. Parece, todavia, que sobre o seu pé esquerdo, está o pé descalço (nestas cenas, as figuras apresentam-se desnudadas, como se sabe) de um segundo caçador, de coxa ampla, que -ainda que, aí, a superfície haja sofrido graves escoriações - se nos afigura ter sido representado de frente, dada a posição do seu pé esquerdo, levemente inclinado para fora. Só subsistem, contudo, como se disse, os membros inferiores das personagens. 
Continuando a observação para a nossa direita, vêem-se dois cães a abocanhar uma lebre, ${ }^{8}$ que se distingue bem, acachapada, perfeitamente dominada já, patas na horizontal, rabo curto: um abocanha a cabeça, o outro a região lombar. O relevo de um dos cães está pouco deteriorado, os olhos bem conservados, coleira, vestígios das orelhas lançadas para trás, como é normal para o momento aí retratado, uma das patas agarra a presa. Do cão que Ihe fica por detrás intui-se apenas a cabeça afilada de galgo, bastante apagada já; também ele está, alongando-se, a abocanhar a lebre, na cabeça, vendo-se a coleira que ostenta. Vê-se outra figura humana, desde a metade inferior do tronco, quase em posição simétrica da primeira.

Com base na cuidada observação feita e nos exemplos a que teve acesso, ${ }^{9}$ Cristina Lapo Oliveira deu indicações ao seu colega Marcos Daniel Silva para que tentasse uma reconstituição do que poderá ter sido a totalidade da cena, que mui gostosamente reproduzo (Fig. 4). O carácter ingénuo do desenho não estará, de facto, muito longe do que terá sido o original. Foram, por consequência, inspirados nesses exemplos os pormenores do vestuário (do "senhor») ou da ausência dele (no caso dos servos), do venábulo (lagobolon), das coleiras dos cães e da forma como o servo os prende.

Uma leitura do extenso e, poderíamos dizer, (ainda) exaustivo artigo de Adolphe Reinach ${ }^{10}$ sobre tudo o que diz respeito a esta actividade entre os Gregos e os Romanos pode ser, de facto, deveras elucidativa para melhor interpretação da cena aqui representada. Assim, nas páginas 686-688, há toda uma informação acerca dos cães usados para a caça, designadamente para a caça à lebre, ainda que esta —embora também apareça representada em sarcófagos e mosaicos acabe por se situar numa categoria inferior em relação às "chasses plus nobles", como o eram as caçadas ao veado e ao javali (p. 691-692). Explicitam-se quais os apetrechos usados (p. 685, Fig. 7354-que tomo a liberdade de reproduzir [Fig. 5]) e, em relação à caça à lebre, descreve-se que «les chasseurs attendaient le lièvre et l'achevaient d'un coup de lagobolon ou d'épieu, quand ils ne la laissaient pas déchirer par les chiens» (p. 692). O lagobolon (venábulo) seria, pois, uma espécie de bastão —que Marcos Daniel imaginou passível de reconstituir aqui, ao ombro de um dos servos. No fundo, a cena é muito simples: os cães levantaram a lebre, aju-

8 Prefiro a classificação de lebre à de coelho, sem nenhuma outra justificação especial a não ser a maior 'dignidade' da caça à lebre, dada a velocidade que é seu apanágio e, por outro lado, atendendo ao focinho afilado dos cães, que sugere estarmos perante a representação de galgos, cães especialmente adestrados, pela sua agilidade, para a caça à lebre. Foi, obviamente, erro grosseiro da minha parte ter interpretado a cena como «de chasse au sanglier» (art. cit., p. 253). Note-se que Jacques AYMARD, no seu livro Essai sur les Chasses Romaines des Origines à la Fin du Siècle des Antonins (Cynegetica), Paris, De Boccard, 1951 [Bibliothèque des Écoles Françaises d'Athènes et de Rome, 171], considera entre as categorias metropolitanas de caçadas «la chasse du sanglier, du cerf et du lièvre», por oposição às coloniais (caçadas ao leão, ao elefante e a outras feras).

9 Refere, de Guntram KOCH, Die Mythologischen Sarkophage, Berlim, 1975, de que, aliás, reproduz as estampas 4 (de Frascati), 18 (do Museu Capitolino), 33 (de Verschollen). Cita também, de Guntram KOCH e Helmut SICHTERMANN, Römischen Sarkophage, Munique, 1982. Note-se que o tema mais corrente é o da caçada ao javali ou ao veado e não à lebre ou ao coelho.

10 In Daremberg, Charles e Saglio, Edmond, Dictionnaire des Antiquités Grecques et Romaines, s. v. venatio (p. 680-700). 
dados pelos batedores e os cães agarram-na perto do senhor, como que a perguntar-lhe o que deseja fazer. Afinal, não seria quiçá assim tão secundário este tipo de caçada, se pensarmos o que se passa nos tempos modernos e se tivermos em conta, por exemplo, que a Fig. 7367 que ilustra o citado artigo (p. 698) e que, com a devida vénia, aqui se reproduz (Fig. 6), representa um jovem caçador sentado, com o seu cão e uma lebre - o que pode significar algum apreço por este tipo de actividade.

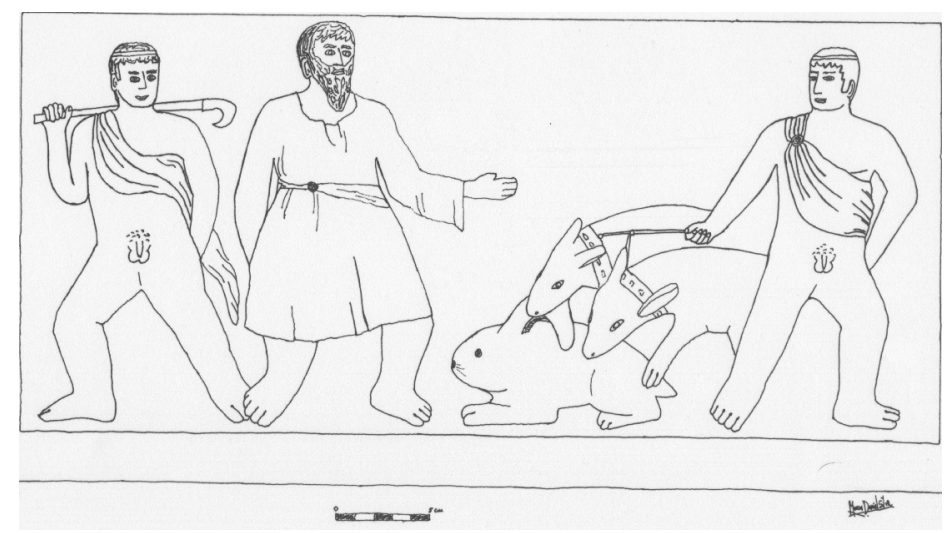

Fig. 4 - Proposta de reconstituição da cena de caça à lebre, elaborada por Daniel Marcos da Silva. Consta do trabalho de Cristina Lapo Oliveira.

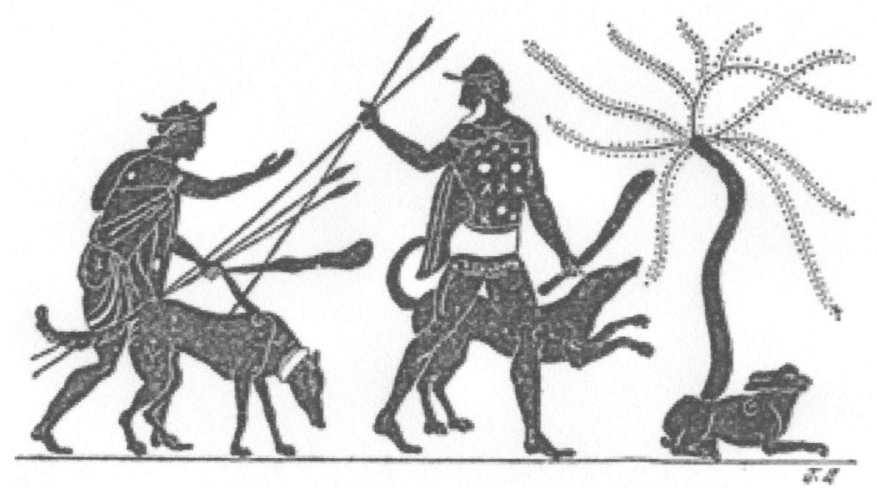

Fig. 5 - Apetrechos de caça ("lances et javelots de chasse"). Retirada de DA, fig. 7354. 


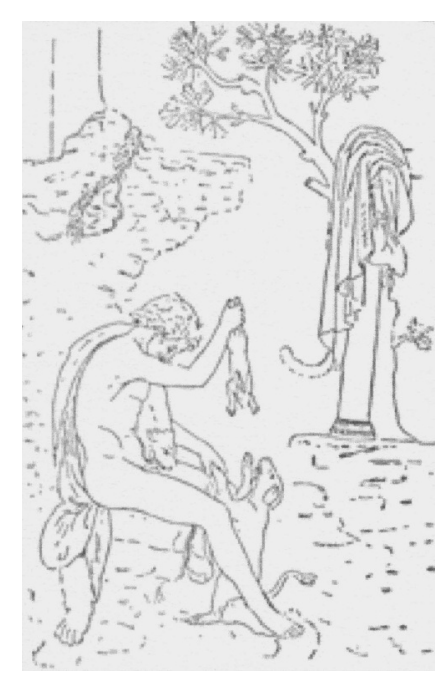

Fig. 6 - "Jeune chasseur assis avec chien et lièvre". Retirada de DA, fig. 7367.

Seríamos, pois, tentados, à primeira vista, a classificar de rudimentar toda a representação; no entanto, observados os pormenores do desenho da cabeça de um dos cães e dos dedos dos pés dos homens, a posição bastante realista da lebre quiçá essa opinião seja de mudar, ainda que, naturalmente, não estejamos perante escultura saída de ateliê de artista. Trata-se, isso sim, da reprodução de uma cena habitualmente observada pelo senhor no seu quotidiano e que, porventura, até poderá ter visto em mosaicos de Conimbriga - se é que teve acesso, por exemplo, à hoje denominada Casa dos Repuxos... - e que mandou executar por um canteiro local. Registe-se, na verdade, que- para além de, como o Doutor Bairrão Oleiro sabiamente assinalou, esses serem «os únicos mosaicos com cenas de caça conhecidos em Portugal» - não deixa de ser bem significativo o facto de, no medalhão $n^{\circ}$ 1.5, se ver «um caçador com um coelho suspenso do pedum», ou seja, do cajado (Fig. 7, que reproduzimos da obra citada). Esse constitui, sem dúvida, exemplo bem paradigmático daquilo que Bairrão Oleiro chamou «o novo gosto pelas representações da vida real», «o apego à cultura tradicional», o «reflexo da vida real sem qualquer alusão mitológica». ${ }^{11}$ Tal reflexão mais acentua a

11 OLEIRO, João Manuel Bairrão, Conimbriga - Casa dos Repuxos. Conímbriga, Museu Monográfico de Conimbriga, 1992, p. 171. Na colecção de mosaicos do Hotel Villa Real, de Madrid, o que tem R-91 como número de inventário e se encontra exposto na «habitación 501 », apresenta um cão a perseguir uma lebre; no comentário que dele faz (in Arte y Religión en el Mediterráneo Antiguo, Madrid, Ediciones Cátedra, 2008, p. 492), José María Blázquez considera ser este um «tema habitual en los mosaicos del Oriente», enumerando uma série de exemplos. 
importância a atribuir a esta representação. O senhor que mandou fazer o monumento de Soure poderá não ter tido acesso ao interior da rica domus conimbricense; sabia, no entanto, quais eram os hábitos de vida dos grandes senhores e dele próprio —porque não? - e isso quis perpetuar ali, para que imorredoiramente o acompanhasse no Além.

Por conseguinte, que significado atribuir-lhe? O do gosto pelas caçadas? A manifestação de significativo poder económico que lhe permitia organizar venationes, porventura no próprio anfiteatro de Conimbriga, sabendo como esse espectáculo tanto era do agrado da população? ${ }^{12}$ A vitória do Homem sobre a Morte, como vitória é, almejada, a captura de uma presa desejada? ${ }^{13}$ Seja como for, um eficaz símbolo de cultura! ${ }^{14}$

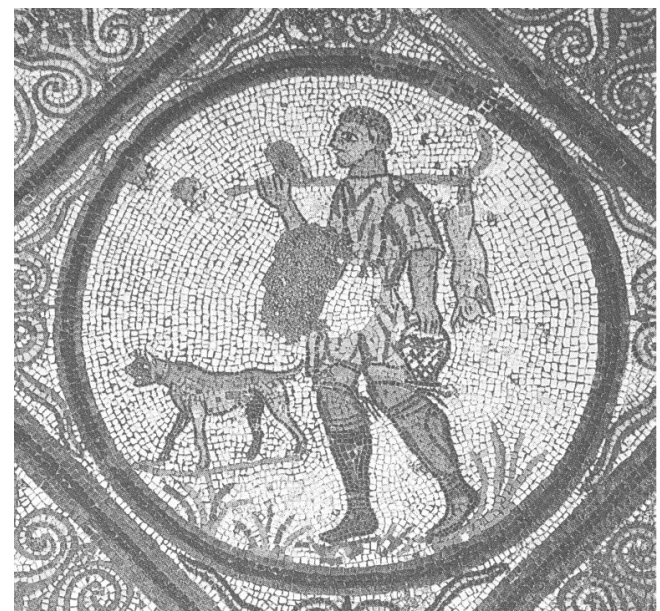

Fig. 7 - Pormenor da estampa 10 do livro de Bairrão Oleiro, sobre os mosaicos da Casa dos Repuxos, de Conímbriga. Um caçador leva, ao ombro, uma lebre pendurada no cajado.

12 Sobre o gosto pelas venationes, há, naturalmente, inúmera bibliografia. Cito apenas, a título de exemplo 'clássico' (digamos assim), o artigo de Georges Lafate, «La venatio dans les jeux de l'amphitéatre», integrado na entrada "venatio» do referido Dictionnaire des Antiquités Grecques et Romaines ( $p$. 700-709).

${ }_{13}$ Cf. as reflexões feitas a esse respeito em CUMONT, Franz, Recherches sur le Symbolisme Funéraire des Romains. Paris, 1942 (Bibliothèque Archéologique et Historique, 35) [reimp. 1966].

14 No volume I da Historia de Barcelona (Ajuntament, Setembro 1991), Alberto Balil comenta, na p. 226, que os sarcófagos com cenas de caça foram produzidos abundantemente pelas oficinas de Roma na 1aㅡ metade do século III, época a que também poderemos fazer remontar o monumento de Soure. 


\section{A EPÍGRAFE}

Num campo epigráfico incompleto —de10 x $24 \mathrm{~cm}$, na actualidade—podemos ler (Fig. 8):

[... 3 linhas] / [... TVMVL?]V SVO CVM MARMORI/[BVS E]T LAQVIARIBVS [sic] DE SVO / [PATRIMON]IO FACIENDVM CVRAVIT

(...) para o seu túmulo [?] com mármores e tecto de caixotões, mandou fazer, a expensas suas.

Altura das letras: 2. Espaços: 1 a 3: 1; 4: 1,5.

Se tivermos em conta que, na cena ao lado, temos as personagens por altura da bacia, poderemos conjecturar que, no sentido vertical, nos faltam três linhas de texto. Da $3^{\underline{a}}$ há vestígios de vértices inferiores de letras, mas torna-se muito hipotético avançar com alguma tentativa de reconstituição. Na verdade, nessas linhas faltantes estaria, necessariamente, a identificação completa do proprietário, precedida, ou não, da dedicatória aos deuses Manes ou a uma outra divindade de sua devoção.

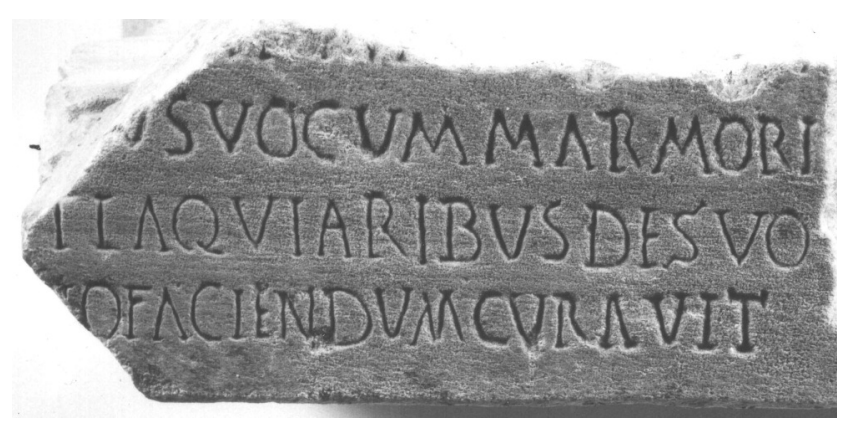

Fig. 8 - A inscrição do monumento de Soure.

Há dificuldade em reconstituir-se o que falta no começo de cada uma das linhas. Assim, se considerarmos que, na última, foi gravada a palavra PATRIMO$\mathrm{NIO}$, nas duas precedentes haveria espaço para mais letras do que as que sugerimos (umas quatro). A opção de suo patrimonio, apesar de exceder o espaço eventualmente disponível tendo em conta um possivel alinhamento à esquerda, afigeura-se-nos bastante verosímil, por ser - como escrevemos (art. cit., 1993, p. 254) - uma fórmula documentada nesta área da Lusitânia e por se identificar, sem grande margem para dúvida, a parte superior do I. Manuela Alves Dias (loco citato) sugeriu sumptu suo em vez de tumulu suo; contudo, para além de a troca de $o$ por $u$ no ablativo singular ser comum (cf. CIL II p. 1189), haveria uma repetição escusada, pois que sumptu suo detém o mesmo significado que de suo ou de suo patrimonio. Por seu turno, o vocábulo tumulus parece adequar-se bem ao carácter 
erudito da epígrafe, pois - ao percorrermos os exemplos hispânicos consignados em http://eda-bea.es/_- verificamos que, para além de um uso corrente na epigrafia cristã dos primeiros tempos, há predominância da sua ocorrência em epitáfios métricos ou de matriz fora do comum.

Não obstante esta argumentação, outro problema subsiste no que concerne ao conteúdo das três linhas iniciais que se perderam: é que, para além da identificação do proprietário, deveria existir aí uma frase de que dependesse o sugerido ablativo tumulu suo. A hipótese de uma disposição testamentária, completada, por exemplo, com [ex testament]u suo é verosímil, mas não nesses termos porque as características físicas, construtivas, do monumento (cum marmoribus et laquearibus) implicam que ele venha identificado imediatamente antes. Há, porém, necessidade de se pensar que aí poderá ter sido expressa uma vontade, a que corresponde, na parte final, a execução (faciendum curavit) e as circunstâncias dessa execução (de suo patrimonio).

Por conseguinte, no que concerne à paginação, era aliciante supor-se um alinhamento à esquerda (contrariado, como se viu, se se optar pela reconstituição da palavra PATRIMONIO, a exigir mais espaço que a solução que preconizo para as duas linhas precedentes). O ordinator não utilizou qualquer pontuação, mas sentese que houve linhas auxiliares, quer pela regularidade dos espaços interlineares e do módulo das letras, quer pela observação do modo como essas mesmas letras são acabadas nos vértices, sempre com um breve traço horizontal, a assinalar, dirse-ia, a passagem da referida linha auxiliar. Isso é evidente, por exemplo, no traçado dos VV, dos AA (este nem sempre com barra intermédia, anote-se), dos II e, de modo especial, nos inusitados desenhos do vértice superior do $\mathrm{R}$ e da barra do T com dois tracinhos em cada extremo.

A gravação foi feita com goiva, ${ }^{15}$ à mão levantada: daí a irregularidade do traçado, actuário, dos caracteres sem linhas rectas ou curvas gravadas com auxílio de recta ou de compasso. De notar o $\mathrm{M}$ da linha 1, cujo vértice intermédio não atinge o nível inferior dos outros dois, sinal que temos sugerido como índice de epígrafe não autêntica, na área da Lusitânia; no caso vertente, todavia, vendo o M da última linha, temos de considerar que tal circunstância anómala é mais uma consequência da gravação segundo minuta desenhada à mão levantada. De registar ainda, do ponto de vista paleográfico, que, no $\mathrm{R}$, a parte superior não é fechada, pois o traço não chega a tocar na haste vertical; que a perna (breve e pouco oblíqua) do $Q$ foi gravada sobre o traçado de um $O$; que também o último $S$ da I. 2 ostenta traços oblíquos nos vértices, a emprestar alguma graciosidade e a acentuar o carácter actuário do conjunto; que é mais curta (por falta de espaço) a barra média do F. Finalmente, observe-se a troca do E por I, em laquiaribus, reflexo nítido da oralidade.

15 Cristina Oliveira escreveu: «O corte é em bisel, mediante a utilização de badame muito pequeno, daí o tamanho das letras ser bastante reduzido» (p. 8). Uma observação mais cuidada leva-me a ter opinião diversa: a gravação foi feita com goiva, instrumento que melhor se adapta, aliás, a este tipo de epígrafe sem rigor geométrico. Por outro lado, o módulo das letras não tem que ver com o instrumento usado mas sim com o espaço disponível para o texto a incluir. 


\section{O MONUMENTO}

As reflexões atrás exaradas acerca da cena representada no baixo-relevo e, agora, as informações veiculadas pelo texto levam-nos, necessariamente, a uma outra questão: estamos, na verdade, perante um mero sarcófago, dado que essas representações são muito próprias desse tipo de monumentos? ${ }^{16}$

No meu primeiro texto, já dava a entender que estes dois fragmentos estariam incorporados num «monument funéraire d'une certaine allure» (p. 253). Mantenho essa opinião, que, aliás, também a observação cuidada feita por Cristina Lapo Oliveira confirma:

«O monumento destinava-se a ser adossado a uma parede, na medida em que podemos observar que apenas possui três faces (ou vestígios destas). [...] A parte posterior do sarcófago prolonga-se mais cerca de $17 \mathrm{~cm}$ para o exterior formando uma cunha, para embutir na parede. Encaixaria, portanto, na parede do fundo de um mausoléu de família (a largura da base, sem esta cunha de encaixe, tinha espaço suficiente para alojar o corpo de um indivíduo, pois mede cerca de $60,6 \mathrm{~cm}$ ). A espessura desta cunha poderia facilmente suportar o peso do corpo da pessoa aí sepultada, assim como o do próprio monumento, o que facilitaria a quem o visitasse aperceber-se da existência do sarcófago assim como do seu texto e decoração». E aduz como exemplos sarcófagos patentes «no Museu Arqueológico de Barcelona, na sala XXVI, que não apresentam a parte posterior trabalhada» (pp. 5-6).

A inserção desta epígrafe no monumento arquitectónico total constitui, por consequência, uma questão em aberto e vamos esperar algo que não será de todo impossível: que, um dia, por ocasião de outros trabalhos no subsolo, venham a ser encontrados mais fragmentos, passíveis de resolver as dúvidas ora subsistentes. Para ser adaptado a tampa de sarcófago, teria de apresentar desde logo características físicas facilitadoras dessa reutilização; contudo, os pormenores aduzidos pelo texto sugerem, de facto, algo mais complexo do que simples sarcófago e apontam mais para o edifício em que o eventual sarcófago seria integrado.

Tem-se discutido a existência de mausoléus no espaço ocidental da Lusitânia romana. Por outro lado, a epígrafe de Laveiras, em que Quinto Flávio Quadrado, fiIho de Marco, da tribo Galéria, aquilífero da II Legião, faz em vida o seu monumento, que quer ornado com uma "estrutura em forma de caramanchão» e adverte que não quer que passe ao herdeiro, ${ }^{17}$ deve ser também aqui chamada à colação, por demonstrar o que eu designei ser o túmulo a «mansão para a eterni-

16 Pode, a este propósito, consultar-se, de Robert TURCAN, Messages d'Outre-Tombe : L'Iconographie des Sarcophages Romains. Paris, De Boccard, 1999.

17 GUERRA, Amílcar, «A propósito do topónimo «Oeiras»: algumas considerações linguísticas e históricas», Estudos Arqueológicos de Oeiras, 17, (2009), pp. 595-605 (sobretudo pp. 600-603); ENCARNAÇÃO, José d", «Oeiras romana. A compreensível convivência», in BOIÇA, Joaquim M. F. [coord.], Encontros de História e Património (1) - Diálogos em Noites de Verão 2006-2007. Oeiras, Espaço e Memória - Associação Cultural de Oeiras, s/ d. [2010], p. 22-37. Disponível em: http://hdl.handle.net/10316/13197. 
dade»:18 quem detém poder económico para o fazer não prescinde de acautelar o que vai ser a sua eterna morada, com o conforto que almeja. De resto, uma visita às necrópoles de Óstia seria argumento mais do que suficiente para o atestar...

Acontece, todavia, que se a utilização de mármores mesmo com efeito decorativo, para revestimento de paredes, não seria invulgar numa região como a Lusitânia, onde o mármore abunda e da sua exploração em tempo de Romanos não restam dúvidas, a menção a laquearia merece redobrada atenção. Primeiro, do ponto de vista arquitectónico: não é comum; antes, pelo contrário, é sinónimo de elevado requinte. Depois, do ponto de vista cultural, uma vez que é termo raramente usado em epigrafia e o que dele se documenta nas fontes literárias reforça esse carácter luxuoso, a denotar também que o proprietário do mausoléu da Soure romana possuía elevado poder económico, sim, mas também uma cultura fora do comum.

Já tive ensejo, na primeira abordagem ao texto, em 1993, de referir ocorrências - epigráficas e literárias - do uso do termo laquearia, mormente na África romana (CIL VIII). Importará, contudo, aduzir mais alguns exemplos, a fim de que melhor se entenda o interesse histórico-cultural deste aparentemente singelo e rude monumento epigrafado.

No Dictionnaire des Antiquités Grecques et Romaines, s. v. «laquear», somos remetidos para a entrada «lacunar, lacunarius, laquear», explicitando-se, de imediato, em nota, que, na verdade, laquear e lacunar não são exactamente a mesma coisa: lacunar é o esquema de caixotão usado nos tectos; laquear era, por seu turno, o conjunto das separações entrecruzadas, entre as quais se encontravam os lacunaria, de forma que uns não poderiam existir sem os outros; com o uso, porém, gerou-se alguma confusão e amiúde se tomava o todo pela parte, de tal modo que, na prática, os termos são equivalentes.

A leitura desse artigo (p. 902-904), saído da pena de Henry Thédenet, é deveras sugestiva, porque dá conta de como esse tipo de tecto se encontra sempre associado a ambientes requintados, como, aliás, a documentação literária comprova. ${ }^{19}$

Assim, na ceia de Trimalquião (PETRÓNIO, Satíricon, 60, 1-3), um cesto de ouro desce do tecto ajoujado de presentes para os convidados:

18 ENCARNAÇÃO, José d', «Mansão para a eternidade...», prólogo ao livro Epigrafia Funerária Romana da Beira Interior - Inovação ou Continuidade?, de Ana Paula Ramos Ferreira, Lisboa, 2004, pp. 911. [Incluído no livro Paisagens da Antiguidade, Lisboa, Apenas Livros, 2009, pp. 19-23].

${ }_{19}$ Nas transcrições seguintes, porei a negro as palavras em análise. Foi-me excepcionalmente útil a consulta da base de dados do Laboratoire d'Analyse Statistique des Langues Anciennes [http://www.cipl.ulg.ac.be/lasla/]. S. v. «laquear», cita: PERSIVS, Satirae, 3, 40; SENECA; Ad Lucilium Epistulae Morales, 90, 15 e 90, 42; TÁCITO, Annales, 4, 69, 1; VERGILIVS, Aeneis, 1, 726 e 8, 25. S. v. «lacunar»: HORATIVS, Carmina, 2, 18, 2; IVVENALIS, Saturae, 1, 56; PETRONIVS, Satyricon, 60, 1 e 60, 3; SENECA, Ad Lucilium Epistulae Morales, 90,9, 114,9 e 115,9. Daí as transcrições que faço a se- 
Nec diu mirari licuit tam elegantes strophas nam repente lacunaria sonare coeperunt totumque triclinium intremuit. Consternatus ego exsurrexi et timui ne per tectum petauristaurius aliquis descenderet nec minus reliqui convivae mirantes erexere vultus expectantes quid novi de caelo nuntiaretur. Ecce autem diductis lacunaribus subito circulus ingens de cupa videlicet grandi excussus demittitur cuius per totum orbem coronae aureae cum alabastris unguenti pendebant.

\section{Ou seja:}

«Não tivemos durante muito tempo a possibilidade de admirar tão belos golpes de destreza. De repente, o tecto de caixotões começou a retumbar e toda a sala de jantar vibrou. Tomado de pânico, levantei-me, receando que pelo tecto descesse algum equilibrista. Não menos espantados, os outros convivas ergueram a cabeça, na expectativa da novidade que o céu lhes anunciava. $E$ eis que de súbito os caixotões se entreabrem e vê-se descer um grande círculo, aparentemente tirado de uma enorme cuba: em redor estavam presas coroas de ouro com alabastros de perfume». ${ }^{20}$

Virgílio, na Eneida $(1,726),{ }^{21}$ ao descrever o banquete que Dido, a rainha de Cartago, ofereceu ao seu apaixonado Eneias, escreve:

[...] fit strepitus tectis vocemque per ampla volutant atria dependent lychni laquearibus aureis incensi et noctem flammis funalia vincunt.

«Ecoa um grande ruído no palácio e a voz dos convivas desdobra-se sob os vastos lambris; dos tectos dourados estão suspensos lustres brilhantes, e as chamas das tochas vencem a noite».22

De novo, pois, um ambiente sui generis... E mais adiante $(8,25)$ :

Sicut aquae tremulum labris ubi lumen aenis sole repercussum aut radiantis imagine lunae omnia pervolitat late loca iamque sub auras erigitur summique ferit laquearia tecti.

«Assim, quando um vaso de bronze a trémula luz da água reflecte o sol ou a imagem da lua brilhante, ela volteia ao longe em todos os lugares, projecta-se nos ares e vai atingir os lambris do tecto» (o. c., p. 136).

Tácito, nos Anais (4, 69, 1):

Tectum inter et laquearia tres senatores haud minus turpi latebra quam detestanda fraude sese abstrudunt foraminibus et rimis aurem admovent.

\footnotetext{
guir. 20 PETRÓNIO, O Satíricon. Mem Martins, Publicações Europa-América, [Livros de Bolso no 68], 1973, (tradução de Jorge de Sampaio), sob o noㅡ 50 (p. 65).

${ }_{21}$ Corrija-se a gralha que passou no meu texto de 1993, onde referi Eneida, 1726.

22 VIRGílLIO, A Eneida. Mem Martins, Livros de Bolso de Publicações Europa-América, no 310, s/ d., p. 28 (tradução de Cascais Franco). No comentário a propósito desta passagem, a que acedi, vem uma explicitação sugestiva: «Laquearia means a «panelled ceiling,» and Eliot's note quotes the passage in the Aeneid that was his source for the Word» (http://eliotswasteland.tripod.com/notes.html).
} 
«Assentaram pois que entre o tecto da casa e o forro do aposento se fossem esconder os três senadores; e procurando assim um esconderijo tão infame como a sua mesma abominável traição, se ajustou que através de certos buracos e aberturas no forro aplicariam os ouvidos para bem perceberem tudo o que se passava em baixo. ${ }^{23}$

Não deixou também Juvenal de usar o termo numa das suas Sátiras $(1,56)$, ao referir-se a um tal Sulpício Galba, que tinha por hábito dormir a sesta, para não presenciar o comportamento de sua mulher, cortejada por Mecenas; um dia, porém, o escravo quis aproveitar a ocasião para provar do seu excelente Falerno e de tal foi impedido: «Olha lá, ó moço! Eu não estou a dormir para tudo!» - Heu, puer! Non omnibus dormio!». Para Juvenal, este olhar para o tecto, fingindo que nada estava a acontecer, não merece ser cantado:

[...] doctus spectare lacunar doctus et ad calicem vigilanti stertere naso cum fas esse putat curam sperare cohortis qui bona donavit praesepibus et caret omni maiorum censu dum pervolat axe citato Flaminiam puer Automedon [...].

«[...] Diestro en mirar al techo, / Diestro en roncar al lado del triclinio / Con la experta nariz puesta en acecho [...]».24

Duas passagens de Séneca, nas suas conhecidas Cartas a Lucílio, são também de referir:

Hodie utrum tandem sapientiorem putas qui invenias quemadmodum in immensam altitudinem crocum latentibus fistulis exprimat qui euripos subito aquarum impetu implet aut siccat et versatilia cenatiorum laquearia ita coagmentat ut subinde alia facies atque alia succedat et totiens tecta quotiens fericula mutentur in eum qui et alliis et sibi hoc monstrat quam nihil nobis natura durum ac difficile imperaverit posse nos habitare sine marmorario ac fabro posse nos vestitos esse sine commercio sericorum posse nos habere usibus nostris necessaria si contenti fuerimus iis quae terra posuit in summo $(90,15)$.

«E nos dias de hoje quem consideras tu como sábio? O técnico que sabe montar repuxos de água perfumada através de canalizações invisíveis, o que é capaz de encher ou esvaziar num instante os canais artificiais, o que sabe dar diversas disposições aos caixotões móveis do tecto de modo a que o salão de banquetes vá mudando de decoração à medida que vão mudando os vários pratos? Ou antes aquele que demonstra, a si mesmo e aos outros, que a natureza nos não impõe nada que seja duro e difícil, que para termos uma casa não carecemos de marmoristas ou marceneiros, que para nos vestirmos não dependemos do comércio da seda, em suma, que para dispormos do essencial à vida quotidiana nos basta aquilo que a terra nos apresenta à superfície? Se a humanidade se dispu-

${ }^{23}$ CARVALHO, José Liberato Freire de (trad.), Os Anais de Tácito Traduzidos em Linguagem Portuguesa por... Tomo I, Paris, J. P. Aillaud, 1830. Agradeço a Ricardo Nobre a informação desta tradução; Ricardo Nobre prepara, com Maria Cristina de Castro-Maia de Sousa Pimentel e J. Filipe Ressurreição, a edição desta tradução clássica.

${ }^{24}$ In Sátiras de Juvenal y Persio traducidas en verso castellano por D. Francisco Dúiza Carmona y D. José M. Vigil. Madrid, Librería de la Viuda de Hernando y Cª , 1892, p. 7. 
sesse a seguir os conselhos de um tal homem imediatamente perceberia que tão ignóbil é o cozinheiro como o soldado!». ${ }^{25}$

Note-se a referência ao que atrás se dizia a propósito do carácter requintado deste tipo de tecto: Séneca alude - e aqui ecoa o que se transcreveu da ceia de Trimalquião - aos «caixotões móveis do tecto de modo a que o salão de banquetes vá mudando de decoração à medida que vão mudando os vários pratos»...

Mais à frente $(90,42)$ :

Non inpendebant celata laquearia sed in aperto iacentes sidera superlabebantur et insigne spectaculum noctium mundus in praeceps agebatur silentio tantum opus ducens.

«Não tinham sobre a cabeça tectos trabalhados; dormindo ao relento, viam deslizar os astros sobre as suas cabeças, viam o sublime espectáculo nocturno da mole imensa do universo em silenciosa rotação» (o. cit., p. 453).

\section{CONCLUSÃO}

Creio ter ficado suficientemente demonstrado quão justificada é a aplicação do adjectivo «singular» a este monumento epigráfico de Soure.

A sua tipologia; o carácter único, nesta zona ocidental da Lusitânia romana, da temática versada no baixo-relevo que o ornamenta; a utilização do vocábulo laquearia nada corrente em textos epigráficos e haurido, decerto, em textos literários, como se viu - apontam não apenas para um caso particular do ager Conimbricensis, porque, a juntar ao que hoje desse ager se conhece (referimo-nos à villa do Rabaçal, por exemplo) e às bem documentadas relações da população da civitas com a capital do Império, ganha cada vez maior relevo a ideia de que esta 'periferia' o é, sim, no aspecto geográfico; não o é, contudo, do ponto de vista económico nem no que concerne à genuína assimilação de hábitos culturais romanos. *

25 SÉNECA, Lúcio Aneu, Cartas a Lucílio. Trad. de J. A. Segurado e Campos. Lisboa, Fundação Calouste Gulbenkian, 2004, p. 443. Agradeço aos meus prezados colegas Aires do Nascimento e Nelson Henrique Silva Ferreira a gentileza de me haverem facultado esta tradução.

* Este estudo insere-se na investigação levada a cabo no âmbito do grupo Epigraphy and lconology of Antiquity and Medieval Ages, do Centro de Estudos Arqueológicos das Universidades de Coimbra e Porto (Unidade I\&D no 281 da Fundação para a Ciência e a Tecnologia). 
